Systematic Review

\title{
Meta-analysis of medical management versus catheter ablation for atrial fibrillation
}

\author{
Yin-jun Mao ${ }^{1, \dagger}$, Hang Wang ${ }^{1, \dagger}$, Jian-xing Chen $^{2}$ and Pin-fang Huang ${ }^{1, *}$ \\ ${ }^{1}$ Department of Pharmacy, First Affiliated Hospital of Fujian Medical University, Chazhong Road NO.20, Fuzhou, 350000, \\ Fujian, P. R. China \\ 2 Department of Anesthesiology, First Affiliated Hospital of Fujian Medical University, Chazhong Road NO.20, Fuzhou, \\ 350000, Fujian, P. R. China \\ ${ }^{*}$ Correspondence: huangpinfang@fimu.edu.cn (Pin-fang Huang) \\ †These authors contributed equally.
}

\section{DOI: $10.31083 /$ i.rcm.2020.03.60}

This is an open access article under the CC BY-NC 4.0 license (https://creativecommons.org/licenses/by-nc/4.0/).

Several observational studies have shown a survival benefit for patients with atrial fibrillation (AF) who are treated with catheter ablation $(C A)$ rather than medical management (MM). However, data from randomized controlled trials (RCTs) are uncertain. Therefore, we performed a meta-analysis of RCTs that compared the benefits of CA and $M M$ in treatment of AF. We searched the Cochrane Library, PubMed, and EMBASE databases for RCTs that compared AF ablation with $M M$ from the time of database establishment up to January 2020 . The risk ratio (RR) with a $95 \%$ confidence interval $(\mathrm{Cl})$ was used as a measure treatment effect. Twenty-six RCTs that enrolled a total of 5788 patients were included in the meta-analysis. In this meta-analysis, the effect of AF ablation depended on the baseline level of left ventricular ejection fraction (LVEF) in the heart failure (HF) patients. AF ablation appears to be of benefit to patients with a lesser degree of advanced HF and better LVEF by reducing mortality. Meanwhile, this mortality advantage was manifested in longterm follow-up. CA increased the risk for hospitalization when it was used as first-line therapy and decreased the risk when used as second-line therapy. CA reduced recurrence of atrial arrhythmia for different types of AF (paroxysmal or persistent AF) and CA-related complications were non-negligible. There was no convincing evidence for a reduction in long-term stroke risk after AF ablation, and additional high quality RCTs are needed to address that issue.

\section{Keywords}

Atrial fibrillation; medical management; catheter ablation; stroke; mortality

\section{Introduction}

Atrial fibrillation (AF) is the most common type of cardiac arrhythmia (Lloyd-Jones et al., 2004), and its prevalence and incidence gradually increase with age. AF is more common in men than in women of all ages (Chugh et al., 2014). AF is the main cause of stroke, and is associated with higher rates of mortality and cardiovascular disease. The major causes of death in patients with $\mathrm{AF}$ are progressive heart failure (HF), cardiac arrest, and stroke (Chiang et al., 2017). AF occurs in $>50 \%$ of patients with HF, and HF occurs in $>33 \%$ of patients with AF. The prognosis for patients with both diseases is worse than the prognosis for patients with only one of the diseases alone (Santhanakrishnan et al., 2016).

In addition to the risk factors and lifestyle management (e.g., alcohol, obesity, sleep apnoea, lack of exercise) as well as stroke prevention (Hart et al., 2007; Kirchhof et al., 2016), rate control and rhythm control are the most common strategies employed for treating AF. A previous large sample randomized controlled trial (RCT) revealed that the use of antiarrhythmic drugs (AADs) for rhythm control in AF treatment provides no survival advantage compared to a rate control strategy (Wyse et al., 2002). Subsequently, several RCTs showed that catheter ablation (CA) is a safe and better method for maintaining sinus rhythm (SR) and preventing AF recurrence than the use of AADs (Forleo et al., 2009; Jais et al., 2008; Pappone et al., 2006; Stabile et al., 2006). Similarly, data from non-randomized studies have consistently indicated that $\mathrm{AF}$ ablation provides greater benefits for treating $\mathrm{AF}$ as measured by clinical hard endpoints and cardiac function tests than treatment by medical management (MM) alone (Mansour et al., 2018; Reynolds et al., 2012). Despite the recent publication of several landmark RCTs that compared CA with MM among AF patients in clinical hard endpoints, the superiority of one strategy over the other remains in doubt. To fill this knowledge gap, we performed a meta-analysis of RCTs comparing CA and MM in patients with AF.

\section{Methods}

\subsection{Literature search}

According to PICOS (Menzies, 2011), we searched the Cochrane Library, PubMed, and EMBASE databases from the time of their establishment up to January 2020 using the following Medical Subject Heading terms and key words: "atrial fibrillation", "catheter ablation", "randomized", "medical therapy", " rhythm control", and "radiofrequency ablation". In addition, 
Table 1. Baseline characteristics of the included trials.

\begin{tabular}{|c|c|c|c|c|c|c|c|c|c|c|c|}
\hline Study/Year & Patients (n) & Mean age (years) & Male (\%) & $\mathbf{L A D}(\mathbf{m m})$ & LVEF (\%) & PEE (n) & CAD (n) & DM (n) & HTN (n) & Crossover to $\mathrm{CA}(\%)$ & Follow up (months) \\
\hline Natale et al., 2000 & $31 / 30$ & $67 \pm 8 / 66 \pm 11$ & $65 / 73$ & NR & $49.4 \pm 5 / 49.6 \pm 3$ & NR & $12 / 11$ & NR & NR & NR & 33 \\
\hline Krittayaphong et al., 2003 & $15 / 15$ & $55 \pm 11 / 49 \pm 15$ & $73 / 53$ & $39.6 \pm 7.7 / 39.2 \pm 7.1$ & $63.7 \pm 10 / 61.8 \pm 9$ & $0 / 0$ & NR & NR & NR & NR & 12 \\
\hline Wazni et al., 2005 & $33 / 37$ & $53 \pm 8 / 54 \pm 8$ & NR & $41 \pm 8 / 42 \pm 7$ & $53 \pm 5 / 54 \pm 6$ & NR & NR & NR & $8 / 10$ & NR & 12 \\
\hline Da Costa et al., 2006 & $52 / 51$ & $78.5 \pm 5 / 78 \pm 5$ & $79 / 82$ & $43 \pm 7 / 43 \pm 6$ & $56 \pm 14 / 54 \pm 14$ & NR & NR & $10 / 11$ & $36 / 34$ & NR & 13 \\
\hline Oral et al., 2006 & $77 / 69$ & $55 \pm 9 / 58 \pm 8$ & $67 / 62$ & $45 \pm 6 / 45 \pm 5$ & $55 \pm 7 / 56 \pm 7$ & $0 / 0$ & $3 / 4$ & NR & NR & 77 & 12 \\
\hline Stabile et al., 2006 & $68 / 69$ & $62 \pm 9 / 62 \pm 11$ & $54 / 64$ & $46 \pm 5 / 45.4 \pm 5.5$ & $59.1 \pm 6.7 / 57.9 \pm 5.8$ & NR & NR & NR & $36 / 34$ & 52 & 12 \\
\hline Pappone et al., 2006 & 99/99 & $55 \pm 10 / 57 \pm 10$ & $70 / 65$ & $40 \pm 6 / 38 \pm 6$ & $60 \pm 8 / 61 \pm 6$ & NR & $2 / 2$ & $5 / 4$ & $56 / 57$ & 42 & 12 \\
\hline Jais et al., 2008 & $53 / 59$ & $50 \pm 11 / 52 \pm 11$ & $85 / 83$ & $39.5 \pm 6 / 40 \pm 6$ & $63 \pm 11 / 66 \pm 7$ & $1 / 7$ & NR & $1 / 2$ & $11 / 18$ & 63 & 12 \\
\hline Forleo et al., 2009 & $35 / 35$ & $63 \pm 9 / 65 \pm 7$ & $57 / 65$ & $44 \pm 6 / 45.2 \pm 5$ & $54.6 \pm 7 / 52.6 \pm 9$ & $5 / 3$ & $7 / 7$ & $35 / 35$ & $22 / 24$ & NR & 12 \\
\hline Wilber et al., 2010 & $106 / 61$ & $56 \pm 9 / 56 \pm 13$ & $69 / 62$ & $40 \pm 1.1 / 40 \pm 1.5$ & $62.3 \pm 2 / 62.7 \pm 2$ & $2 / 2$ & NR & $10 / 7$ & $51 / 30$ & 59 & 9 \\
\hline MacDonald et al., 2011 & $22 / 19$ & $62 \pm 7 / 64 \pm 8$ & $77 / 79$ & NR & $16.1 \pm 7.1 / 19.6 \pm 5.5$ & $2 / 2$ & $11 / 9$ & $7 / 4$ & $14 / 11$ & 0 & 6 \\
\hline Nielsen et al., 2012 & $146 / 148$ & $56 \pm 9 / 54 \pm 10$ & $68 / 72$ & $40 \pm 6 / 40 \pm 5$ & $>60 />60$ & $6 / 5$ & $6 / 2$ & $6 / 10$ & $43 / 53$ & 36 & 24 \\
\hline Packer et al., 2013 & $163 / 82$ & $57 \pm 9 / 56 \pm 9$ & $77 / 78$ & $40 \pm 5 / 41 \pm 6$ & $60 \pm 6 / 61 \pm 6$ & $0 / 0$ & $13 / 8$ & $11 / 7$ & $67 / 37$ & 79 & 12 \\
\hline Pokushalov et al., 2013 & $77 / 77$ & $56 \pm 7 / 57 \pm 7$ & $73 / 77$ & $45 \pm 7 / 46 \pm 5$ & $57 \pm 6 / 58 \pm 5$ & $5 / 6$ & $8 / 10$ & $9 / 7$ & $24 / 29$ & 56 & 36 \\
\hline Jones et al., 2013 & $26 / 26$ & $64 \pm 10 / 62 \pm 9$ & $81 / 92$ & $50 \pm 6 / 46 \pm 7$ & $22 \pm 8 / 25 \pm 7$ & NR & $11 / 13$ & NR & NR & 3.8 & 12 \\
\hline Zhang et al., 2014 & $101 / 100$ & $60 \pm 11 / 58 \pm 10$ & $70 / 67$ & $45.8 \pm 6 / 45.7 \pm 6$ & $57.9 \pm 6 / 57.5 \pm 7$ & $10 / 6$ & $11 / 13$ & $19 / 20$ & $52 / 48$ & 24 & 24 \\
\hline Mont et al., 2014 & $98 / 48$ & $55 \pm 9 / 55 \pm 9$ & $78 / 77$ & $41 \pm 5 / 42 \pm 5$ & $61 \pm 8 / 60 \pm 9$ & $4 / 2$ & NR & NR & $46 / 19$ & 48 & 12 \\
\hline Hummel et al., 2014 & $138 / 72$ & $60 \pm 8 / 61 \pm 8$ & $83 / 83$ & $45 \pm 5 / 46 \pm 5$ & $54 \pm 7 / 55 \pm 6$ & $0 / 0$ & $28 / 12$ & $22 / 8$ & $84 / 40$ & 60 & 6 \\
\hline Hunter et al., 2014 & $26 / 24$ & $55 \pm 12 / 60 \pm 10$ & $96 / 96$ & $52 \pm 11 / 50 \pm 10$ & $31.8 \pm 7.7 / 33.7 \pm 12$ & NR & NR & NR & $8 / 8$ & 0 & 6 \\
\hline Morillo et al., 2014 & $66 / 61$ & $56 \pm 9 / 54 \pm 12$ & $77 / 74$ & $40 \pm 5 / 43 \pm 5$ & $61.4 \pm 5 / 60.8 \pm 7$ & $3 / 4$ & $6 / 2$ & $1 / 4$ & $28 / 25$ & 43 & 24 \\
\hline Sohara et al., 2016 & $100 / 43$ & $59 \pm 10 / 61 \pm 10$ & $80 / 81$ & $38.3 \pm 6 / 38.3 \pm 5$ & $66.7 \pm 6 / 66.5 \pm 7$ & NR & $3 / 2$ & $3 / 4$ & $51 / 24$ & 79 & 9 \\
\hline Di Biase et al., 2016 & $102 / 101$ & $62 \pm 10 / 60 \pm 11$ & $75 / 73$ & $47 \pm 4.2 / 48 \pm 4.9$ & $29 \pm 5 / 30 \pm 8$ & NR & $63 / 66$ & $22 / 24$ & $46 / 48$ & NR & 24 \\
\hline Prabhu et al., 2017 & $33 / 33$ & $59 \pm 11 / 62 \pm 9$ & $94 / 88$ & $48 \pm 5.5 / 47 \pm 8.2$ & $32 \pm 9 / 34 \pm 8$ & $2 / 0$ & $0 / 0$ & $4 / 5$ & $13 / 12$ & 9 & 6 \\
\hline Marrouche et al., 2018 & $179 / 184$ & $64 \pm 3 / 64 \pm 3$ & $87 / 84$ & $48 \pm 1.5 / 49.5 \pm 8.3$ & $31.5 \pm 1.7 / 32.5 \pm 2.2$ & $21 / 21$ & $72 / 96$ & $43 / 67$ & $129 / 136$ & 15.6 & 38 \\
\hline Packer et al., 2019 & $1108 / 1096$ & $68 \pm 5 / 67 \pm 5$ & $63 / 63$ & NR & NR & $117 / 103$ & $201 / 216$ & $280 / 281$ & $876 / 900$ & 27.5 & 48 \\
\hline Kuck et al., 2019 & $100 / 95$ & $65 \pm 8 / 65 \pm 8$ & $88 / 92$ & $50 \pm 6 / 51 \pm 5$ & $28 \pm 9.5 / 24 \pm 8.8$ & NR & $30 / 40$ & $24 / 22$ & $56 / 55$ & 4 & 12 \\
\hline
\end{tabular}

Data are presented as patients receiving CA/patients receiving MM. Age is given as mean \pm SD. CA: catheter ablation; CAD: coronary artery disease; DM: diabetes mellitus; HTN: hypertension; LAD: left atrial diameter; LVEF: left ventricular ejection fraction; MM: medical management; NR: not reported; PEE: previous embolic events. 


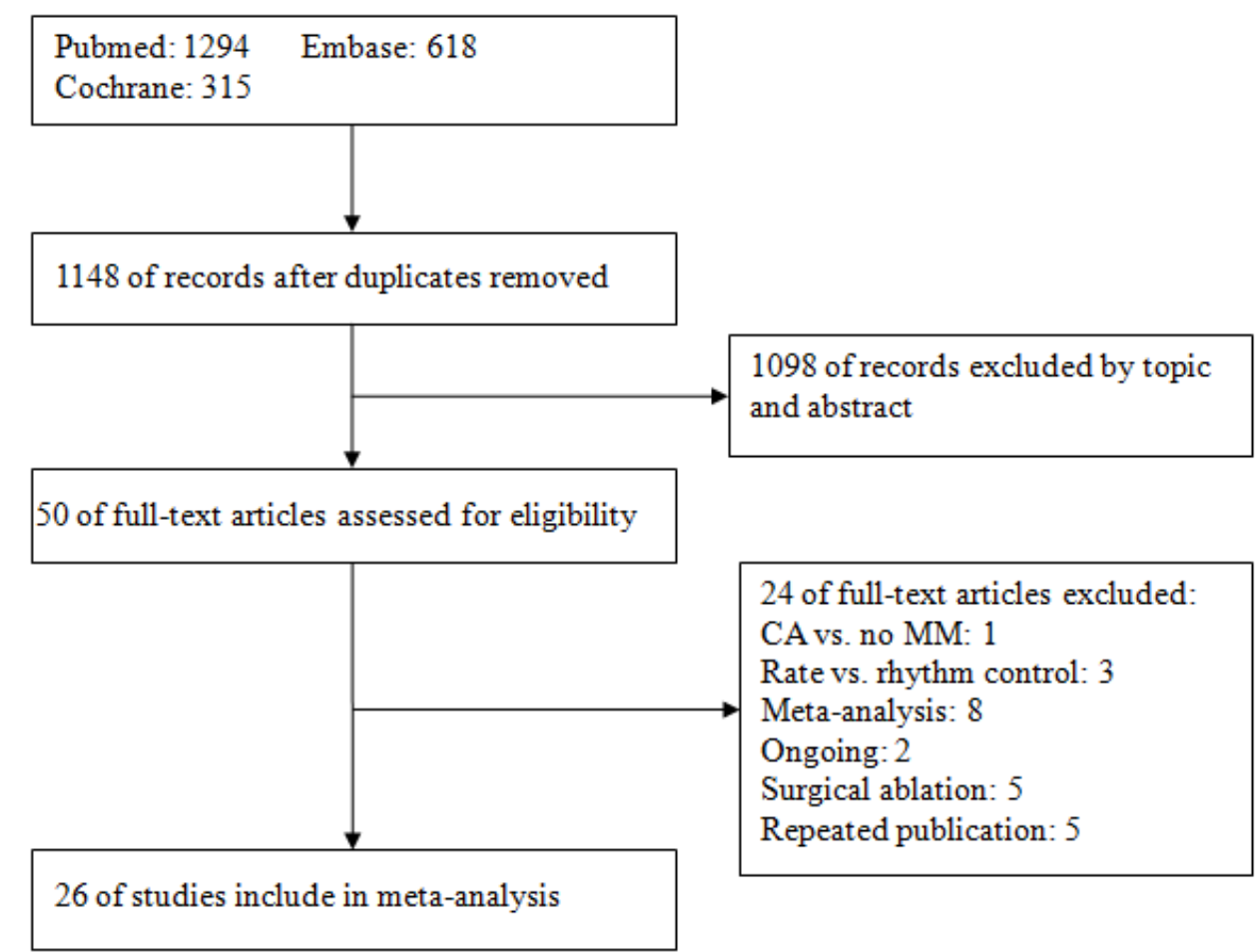

Fig. 1. Flow diagram showing the study selection process for the meta-analysis. The number of studies shown at the bottom of the flow chart represents studies that were ultimately considered eligible for inclusion in this meta-analysis.

we searched the website www.ClinicalTrials.gov to identify relevant information from ongoing trials that have not yet been published. The search strategies used were not restricted by year of publication or language.

\subsection{Inclusion and exclusion criteria}

All relevant RCTs that reported at least one outcome of interest were collected. The patients in those trials had either paroxysmal $\mathrm{AF}$ or persistent $\mathrm{AF}$, and also included $\mathrm{AF}$ patients with $\mathrm{HF}$. If outcome data for recurrence of atrial arrhythmia with both on-drug and off-drug therapy are available, the off-drug data are used. We excluded trials in which CA was used in both therapeutic arms, and as part of a surgical operation. The Cochrane risk of bias assessment tool was used to assess the risk of bias in the included trials (Higgins et al., 2011).

\subsection{Data extraction}

The following information was recorded for each trial included in the meta-analysis: last name of the first author, publication year, sample size in each arm, mean age of the patients, proportion of males in each arm, percentage of patients who crossed-over from a MM group to a CA group, and patient follow-up duration. Additionally, data pertaining to left atrium diameter (LAD), left ventricular ejection fraction (LVEF), previous embolic events (PEEs), hypertension (HTN), coronary artery disease (CAD), and diabetes mellitus (DM) were also recorded. Two investigators independently extracted the data and then analyzed each trial for the outcomes of interest per treatment arm. Any differences of opinion were resolved via discussion.

\subsection{Outcome measures}

The primary outcome was all-cause mortality. The secondary outcomes were recurrence of atrial arrhythmia, stroke/transient ischemic attack (TIA), hospitalization, major bleeding events, pulmonary vein stenosis, and pericardial complications (combination of tamponade, effusion, perforation, pericarditis, and hemorrhage). The definitions of the endpoints were taken as reported in the included trials.

\subsection{Statistical analysis}

Measurements of treatment effect for the endpoints are reported as a pooled risk ratio (RR) with a $95 \%$ confidence interval $(\mathrm{CI})$. Heterogeneity was evaluated according to the $I^{2}$ statistic. Values $\leq 50 \%$ and $>50 \%$ indicated low and high degrees of heterogeneity, respectively. A fixed effect model was used, except when $I^{2}$ was $>50 \%$, in which case, a random effects model was used. The consistency of results was tested by a sensitivity analysis (stepwise exclusion of one study at a time). Potential publication bias was evaluated by visual inspection of a Begg's funnel plot and the Egger's linear regression method (Egger et al., 1997). All reported $P$-values are bilateral, and a $P$-value $<0.05$ was considered to be statistically significant. All analyses were performed using STATA software (version 12.0) and RevMan software (version 5.3.5).

\section{Results}

The study selection steps are summarized in Fig. 1. A total of 2227 articles were identified during the literature search. After reviewing the full text of each possibly appropriate article, 26 articles that met the selection criteria were included in this meta-analysis. 


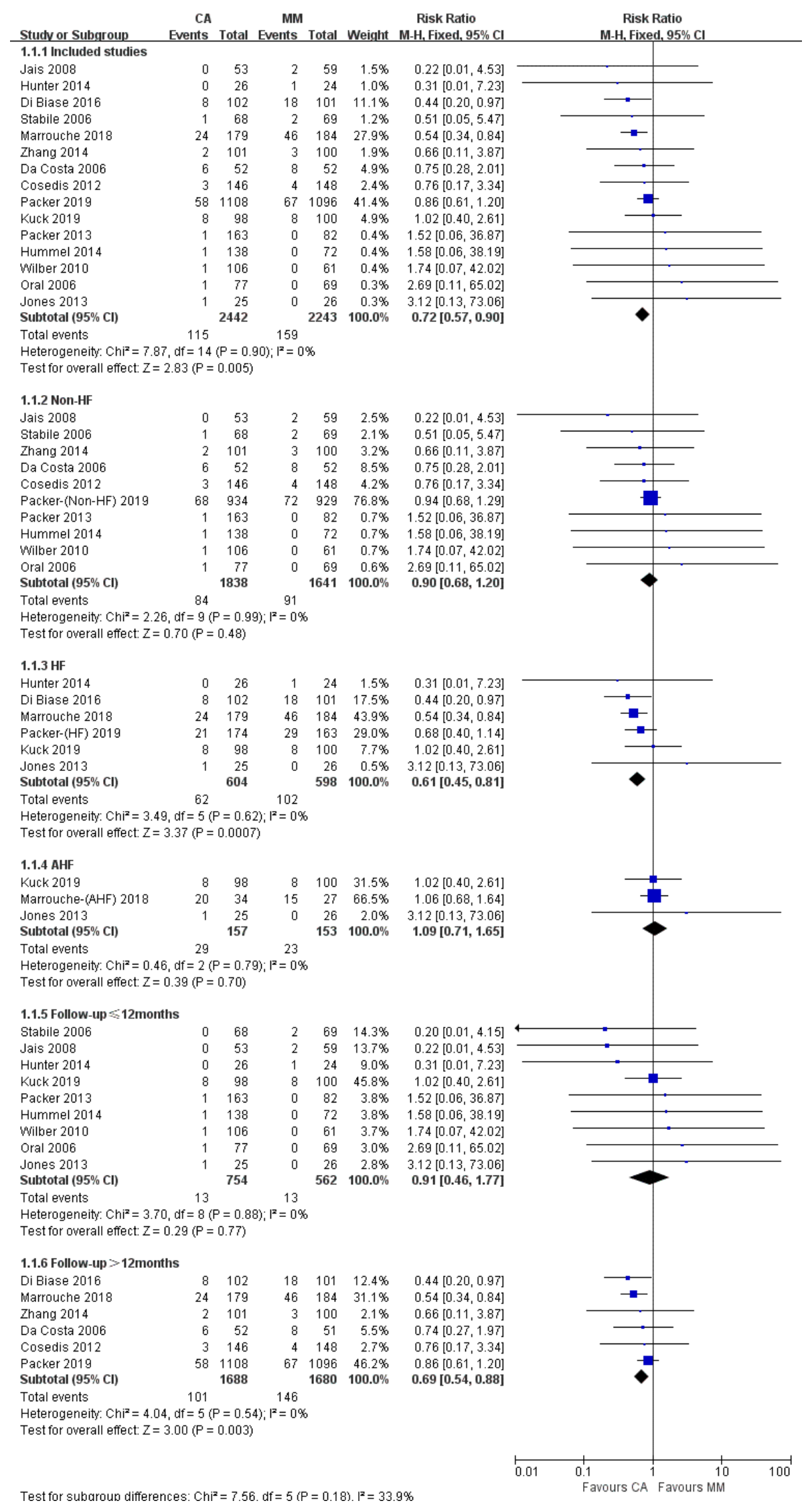

Fig. 2. The pooled outcome of all-cause mortality. A forest plot illustrating the all-cause mortality during follow-up among AF patients randomized to CA versus MM. Packer-(Non-HF), Packer-(HF), and Marrouche-(AHF) used composite endpoints. 
Table 2. Risks of bias in the included trials according to the Cochrane risk of bias assessment tool.

\begin{tabular}{|c|c|c|c|c|c|c|c|}
\hline Author/Study(year) & $\begin{array}{c}\text { Random } \\
\text { sequence } \\
\text { generation } \\
\text { (selection } \\
\text { bias) }\end{array}$ & $\begin{array}{l}\text { Allocation } \\
\text { concealment } \\
\text { (selection } \\
\text { bias) }\end{array}$ & $\begin{array}{l}\text { Blinding } \\
\text { of participants } \\
\text { and personnel } \\
\text { (performance } \\
\text { bias) }\end{array}$ & $\begin{array}{c}\text { Blinding } \\
\text { of outcome } \\
\text { assessment } \\
\text { (detection } \\
\text { bias) }\end{array}$ & $\begin{array}{c}\text { Incomplete } \\
\text { outcome } \\
\text { data } \\
\text { (attrition } \\
\text { bias) }\end{array}$ & $\begin{array}{l}\text { Selective } \\
\text { reporting } \\
\text { (reporting } \\
\text { bias) }\end{array}$ & $\begin{array}{c}\text { Other } \\
\text { bias }\end{array}$ \\
\hline Natale et al., 2000 & Unlcear & Low & High & High & Low & Low & Unlcear \\
\hline Krittayaphong et al., 2003 & Unclear & Unclear & Unclear & Unclear & Unclear & Unclear & Unclear \\
\hline Wazni et al., 2005 & Low & High & Unclear & Unclear & Low & Low & Unclear \\
\hline Da Costa et al., 2006 & Unclear & Unclear & Unclear & Unclear & Unclear & Unclear & Unclear \\
\hline Oral et al., 2006 & Low & Unclear & Unclear & Unclear & Low & Unclear & High \\
\hline Stabile et al., 2006 & Low & Unclear & High & Low & Low & Low & High \\
\hline Pappone et al., 2006 & Unclear & Unclear & High & Low & Low & Low & Unclear \\
\hline Jais et al., 2008 & Low & Unclear & Low & Unlcear & Low & Low & High \\
\hline Forleo et al., 2009 & Low & High & Unclear & Unlcear & Low & Low & Unlcear \\
\hline Wilber et al., 2010 & Low & Low & High & Unlcear & Low & Low & High \\
\hline MacDonald et al., 2011 & Low & Low & High & High & Low & Low & Unclear \\
\hline Nielsen et al., 2012 & Low & Low & High & Low & Low & Low & Unclear \\
\hline Packer et al., 2013 & Unlcear & Low & High & Unclear & High & Low & High \\
\hline Pokushalov et al., 2013 & Low & Low & High & Low & Low & Low & High \\
\hline Jones et al., 2013 & Low & High & High & Low & Low & Low & Unclear \\
\hline Zhang et al., 2014 & Low & High & High & Low & Low & Low & Unclear \\
\hline Mont et al., 2014 & Low & High & High & Unclear & Low & Low & Unclear \\
\hline Hummel et al., 2014 & Unclear & Unclear & Unclear & Unclear & Low & Unclear & High \\
\hline Hunter et al., 2014 & Low & Low & High & High & Low & Low & Unclear \\
\hline Morillo et al., 2014 & Low & Unclear & Unclear & Low & Low & Low & Unclear \\
\hline Sohara et al., 2016 & Unlcear & Unclear & High & Low & High & Low & High \\
\hline Di Biase et al., 2016 & Low & Low & High & High & High & Low & Unlcear \\
\hline Prabhu et al., 2017 & Low & Low & High & High & Low & Low & Unlcear \\
\hline Marrouche et al., 2018 & Low & Low & High & Unclear & High & Low & Unlcear \\
\hline Packer et al., 2019 & Low & Low & High & Low & Low & Low & Unlcear \\
\hline Kuck et al., 2019 & Low & Low & High & Low & High & Low & Unlcear \\
\hline
\end{tabular}

\subsection{Characteristics of the eligible studies}

The meta-analysis included 26 RCTs, with a total of 5788 patients (3054 in the CA arm and 2734 in the MM arm). The 26 trials were published between 2000 and 2019 (Da Costa et al., 2006; Di Biase et al., 2016; Forleo et al., 2009; Hummel et al., 2014; Hunter et al., 2014; Jais et al., 2008; Jones et al., 2013; Krittayaphong et al., 2003; Kuck et al., 2019; MacDonald et al., 2011; Marrouche et al., 2018; Mont et al., 2014; Morillo et al., 2014; Natale et al., 2000; Nielsen et al., 2012; Oral et al., 2006; Packer et al., 2013, 2019; Pappone et al., 2006; Pokushalov et al., 2013; Prabhu et al., 2017; Sohara et al., 2016; Stabile et al., 2006; Wazni et al., 2005; Wilber et al., 2010; Zhang et al., 2014). Six trials were conducted at one center (Hunter et al., 2014; Jones et al., 2013; Krittayaphong et al., 2003; Pappone et al., 2006; Pokushalov et al., 2013; Zhang et al., 2014), and the remaining trials were multicenter trials. One trial included only patients with diabetes (Forleo et al., 2009), and seven trials included patients with HF (Di Biase et al., 2016; Hunter et al., 2014; Jones et al., 2013; Kuck et al., 2019; MacDonald et al., 2011; Marrouche et al., 2018; Prabhu et al., 2017). Table 1 provides the baseline characteristics of the included trials. The patients in 9 trials were followed up for $>12$ months. Many patients had a history of HTN. The data pertaining to, LAD, LVEF, CAD, and DM were similar in the groups of patients (CA intervention and $\mathrm{MM}$ ).
The PEEs included stroke, TIA, deep vein thrombosis, pulmonary embolism, and other peripheral embolisms. Each trial required the participants to take an oral anticoagulant drug on a regular basis starting at least three weeks prior to ablation (international standardization ratio between 2 and 3), and then continue taking the drug for 1 to 12 months after ablation. The blanking period after ablation ranged from 1 to 3 months.

The medications used in the MM arms of the studies were mostly class I and class III AADs (single or combined use), and the AADs in three RCTs were limited to amiodarone (Da Costa et al., 2006; Di Biase et al., 2016; Krittayaphong et al., 2003). In four RCTs (Hunter et al., 2014; Jones et al., 2013; MacDonald et al., 2011; Prabhu et al., 2017), the patients in the MM arm used only rate control medications. In the CA arms, one trial used cryoballoon ablation technology (Packer et al., 2013) and another trial used hotballoon ablation (Sohara et al., 2016). CA was performed as first-line therapy in three trials (Morillo et al., 2014; Nielsen et al., 2012; Wazni et al., 2005), and as second-line therapy in the remaining trials. All trials included pulmonary vein isolation, and most reported additional linear ablation at the discretion of the operator. A complete summary of the risk of bias in the included trials is shown in Table 2. 
Table 3. Complications related to CA.

\begin{tabular}{|c|c|c|c|c|c|}
\hline & $\begin{array}{l}\text { Death, } \\
\text { N }(\%)\end{array}$ & $\begin{array}{c}\text { Stroke/ } \\
\text { TIA, N (\%) }\end{array}$ & $\begin{array}{c}\text { Major bleeding, } \\
\mathbf{N}(\%)\end{array}$ & $\begin{array}{c}\text { Pulmonary vein stenosis, } \\
\text { N }(\%)\end{array}$ & $\begin{array}{c}\text { Pericardial complications, } \\
\mathbf{N}(\%)\end{array}$ \\
\hline Natale $(\mathrm{N}=31)$ & $0(0.0 \%)$ & $0(0.0 \%)$ & $0(0.0 \%)$ & $0(0.0 \%)$ & $0(0.0 \%)$ \\
\hline Krittayaphong $(\mathrm{N}=15)$ & $0(0.0 \%)$ & $1(6.7 \%)$ & $0(0.0 \%)$ & $0(0.0 \%)$ & $0(0.0 \%)$ \\
\hline Wazni (N=33) & $0(0.0 \%)$ & $0(0.0 \%)$ & $0(0.0 \%)$ & $2(6.1 \%)$ & $0(0.0 \%)$ \\
\hline Da Costa $(\mathrm{N}=52)$ & $0(0.0 \%)$ & $0(0.0 \%)$ & $0(0.0 \%)$ & $0(0.0 \%)$ & $0(0.0 \%)$ \\
\hline Oral $(N=77)$ & $0(0.0 \%)$ & $0(0.0 \%)$ & $0(0.0 \%)$ & $0(0.0 \%)$ & $0(0.0 \%)$ \\
\hline Stabile $(\mathrm{N}=68)$ & $0(0.0 \%)$ & $0(0.0 \%)$ & $0(0.0 \%)$ & $0(0.0 \%)$ & $1(1.5 \%)$ \\
\hline Pappone (N=99) & $0(0.0 \%)$ & $1(1.0 \%)$ & $0(0.0 \%)$ & $0(0.0 \%)$ & $1(1.0 \%)$ \\
\hline Jais $(\mathrm{N}=53)$ & $0(0.0 \%)$ & $0(0.0 \%)$ & $2(3.8 \%)$ & $1(1.9 \%)$ & $2(3.8 \%)$ \\
\hline Forleo $(\mathrm{N}=35)$ & $0(0.0 \%)$ & $0(0.0 \%)$ & $0(0.0 \%)$ & $0(0.0 \%)$ & $0(0.0 \%)$ \\
\hline Wilber $(\mathrm{N}=106)$ & $0(0.0 \%)$ & $0(0.0 \%)$ & $0(0.0 \%)$ & $0(0.0 \%)$ & $1(0.9 \%)$ \\
\hline MacDonald $(\mathrm{N}=22)$ & $0(0.0 \%)$ & $0(0.0 \%)$ & $2(9.1 \%)$ & $0(0.0 \%)$ & $2(9.1 \%)$ \\
\hline Nielsen (N=146) & $1(0.7 \%)$ & $1(0.7 \%)$ & $0(0.0 \%)$ & $1(0.7 \%)$ & $3(2.1 \%)$ \\
\hline Packer (2013) $(\mathrm{N}=163)$ & $0(0.0 \%)$ & $1(0.6 \%)$ & $3(1.8 \%)$ & $5(3.1 \%)$ & $1(0.6 \%)$ \\
\hline Pokushalov (N=77) & $0(0.0 \%)$ & $0(0.0 \%)$ & $2(2.6 \%)$ & $0(0.0 \%)$ & $2(2.6 \%)$ \\
\hline Jones $(\mathrm{N}=25)$ & $0(0.0 \%)$ & $0(0.0 \%)$ & $1(4.0 \%)$ & $0(0.0 \%)$ & $1(4.0 \%)$ \\
\hline Zhang (N=101) & $0(0.0 \%)$ & $2(2.0 \%)$ & $1(1.0 \%)$ & $0(0.0 \%)$ & $1(1.0 \%)$ \\
\hline Mont (N=98) & $0(0.0 \%)$ & $0(0.0 \%)$ & $0(0.0 \%)$ & $1(1.0 \%)$ & $3(3.1 \%)$ \\
\hline Hummel (N=138) & $0(0.0 \%)$ & $4(2.9 \%)$ & $0(0.0 \%)$ & $5(3.6 \%)$ & $5(3.6 \%)$ \\
\hline Hunter $(\mathrm{N}=26)$ & $0(0.0 \%)$ & $1(3.8 \%)$ & $1(3.8 \%)$ & $0(0.0 \%)$ & $1(3.8 \%)$ \\
\hline Morillo (N=66) & $0(0.0 \%)$ & $0(0.0 \%)$ & $4(6.0 \%)$ & $1(1.5 \%)$ & $4(6.1 \%)$ \\
\hline Sohara $(\mathrm{N}=100)$ & $0(0.0 \%)$ & $2(2.0 \%)$ & $0(0.0 \%)$ & $7(7.0 \%)$ & $0(0.0 \%)$ \\
\hline Di Biase $(\mathrm{N}=102)$ & $0(0.0 \%)$ & $0(0.0 \%)$ & $0(0.0 \%)$ & $0(0.0 \%)$ & $1(1.0 \%)$ \\
\hline Prabhu $(\mathrm{N}=33)$ & $0(0.0 \%)$ & $0(0.0 \%)$ & $2(6.0 \%)$ & $0(0.0 \%)$ & $0(0.0 \%)$ \\
\hline Marrouche $(\mathrm{N}=179)$ & $0(0.0 \%)$ & $0(0.0 \%)$ & $4(2.2 \%)$ & $1(0.6 \%)$ & $3(1.7 \%)$ \\
\hline Packer (2019) $(\mathrm{N}=1108)$ & $0(0.0 \%)$ & $0(0.0 \%)$ & $0(0.0 \%)$ & $1(0.09 \%)$ & $8(0.7 \%)$ \\
\hline Kuck (N=98) & $1(1.0 \%)$ & $0(0.0 \%)$ & $0(0.0 \%)$ & $0(0.0 \%)$ & $2(2.0 \%)$ \\
\hline Total $(\mathrm{N}=\mathbf{3 0 5 1})$ & $2(0.06 \%)$ & $13(0.4 \%)$ & $22(0.7 \%)$ & $25(0.8 \%)$ & $42(1.4 \%)$ \\
\hline
\end{tabular}

\subsection{End points}

A total of 274 deaths were reported (115 in the composite $\mathrm{CA}$ arm and 159 in the composite MM arm), including 2 periprocedural deaths. CA was associated with a statistically significant reduction in all-cause mortality in AF patients when compared with the MM patients, with a low degree of heterogeneity (RR: $0.72 ; 95 \%$ CI: 0.57 to $0.90, P=0.005 ; I^{2}=0$ ). A subgroup analysis showed there was no significant difference in allcause mortality among AF patients with non-HF or advanced heart failure (AHF) (defined as New York Heart Association functional class II to IV symptoms after optimal HF therapy, persistent AF, and LVEF $\leq 35 \%$ ) between groups [(RR: 0.90 ; 95\% CI: 0.68 to $\left.1.20, P=0.48 ; I^{2}=0\right)(\mathrm{RR}: 1.09 ; 95 \% \mathrm{CI}: 0.71$ to $1.65, P=$ $\left.0.70 ; I^{2}=0\right)$ ], while HF patients treated with CA had a statistically significant reduced rate of all-cause mortality (RR: 0.61 ; $95 \%$ CI: 0.45 to $0.81, P=0.0007 ; I^{2}=0 \%$ ). No significant difference was found regarding the intermediate-term (follow-up $\leq$ 12 months) all-cause mortality in both groups (RR: $0.91 ; 95 \% \mathrm{CI}$ : 0.46 to $1.77, P=0.77 ; I^{2}=0 \%$ ), while CA was found to decrease long-term (follow-up $>12$ months) mortality compared with MM (RR: $0.69 ; 95 \%$ CI: 0.54 to $0.88, P=0.003 ; I^{2}=0 \%$ ) (Fig. 2 ).

The Packer-(Non-HF) and Packer-(HF) subgroup analysis used a composite endpoint (death, disabling stroke, serious bleeding, or cardiac arrest) (Packer et al., 2019), and the Marrouche-(AHF) subgroup analysis also used a composite endpoint (death or admis- sion for worsening HF) (Marrouche et al., 2018). Therefore, in our subgroup analysis, we conducted an additional sensitivity analysis to test the stability of all-cause mortality results for Non-HF, HF, and AHF patients. The sensitivity analysis proved the results to be very stable (Fig. 3).

Next, we analyzed the rates of hospitalization in 14 trials, and found a large degree of heterogeneity (RR: $0.67 ; 95 \% \mathrm{CI}: 0.52$ to 0.87, $P=0.002 ; I^{2}=83 \%$; Fig. 4). The 3 trials in which CA was used as first-line therapy showed similar risks for hospitalization in the two arms (RR: $0.74 ; 95 \%$ CI: 0.33 to $1.68, P=0.48 ; I^{2}=85 \%$; Fig. 4). However, a sensitivity analysis showed that the statistical significance was found and the heterogeneity vanished when the study by Wazni et al. (2005) was excluded from the analysis (RR: 1.22; $95 \% \mathrm{CI}: 1.03$ to $1.45, P=0.02 ; I^{2}=0 \%$; Fig. 5). In the study by Wazni et al. (2005), only hospitalizations that occurred after the initial 2-month period were considered, during which, the first two months could not be reflected. Therefore, the study by Wazni et al. (2005) was the main source of heterogeneity in the CA first-line treatment subgroup. In contrast, CA reduced the risk for hospitalization in the remaining trials (RR: 0.61; 95\% CI: 0.46 to $0.81, P=0.0006 ; I^{2}=77 \%$; Fig. 4 ), and sensitivity analyses showed that the statistical significance of that finding remained after the serial exclusions of 11 trials.

There were 34 strokes/TIAs in the CA arm and 27 in the MM arm (follow-up periods ranged from 6 to 48 months). No dif- 
Table 4. Outcome for recurrence of atrial arrhythmia in AF patients with normal or reduced LVEF who underwent $\mathrm{CA}$ or $\mathrm{MM}$ in the included trials.

\begin{tabular}{|c|c|c|c|c|c|c|c|}
\hline $\begin{array}{l}\text { Recurrence of } \\
\text { atrial arrhythmia }\end{array}$ & $\begin{array}{l}\text { No. of } \\
\text { studies }\end{array}$ & $\begin{array}{l}\text { Patients } \\
\text { CA/MM }\end{array}$ & $\begin{array}{c}\text { Events } \\
\text { CA/MM }\end{array}$ & $P$ value & $\begin{array}{c}\text { Effect estimate } \\
\text { RR (95\% CI) }\end{array}$ & $I^{2}$ & $\begin{array}{c}\text { Incidence } \\
\text { after } \mathrm{CA} / \mathrm{MM}\end{array}$ \\
\hline Overall & 26 & $2533 / 2249$ & $882 / 1525$ & $<0.00001$ & $0.43(0.37,0.51)$ & $82 \%$ & $34.8 \% / 67.8 \%$ \\
\hline \multicolumn{8}{|l|}{ Follow-up duration } \\
\hline Follow-up $\geq 1$ year & 20 & $2113 / 2003$ & $730 / 1309$ & $<0.00001$ & $0.43(0.36,0.53)$ & $83 \%$ & $34.5 \% / 65.4 \%$ \\
\hline Follow-up $\geq 2$ years & 8 & $1313 / 1330$ & $531 / 858$ & $<0.00001$ & $0.58(0.48,0.69)$ & $72 \%$ & $40.4 \% / 64.5 \%$ \\
\hline Follow-up $\geq 3$ years & 3 & $867 / 890$ & $398 / 623$ & 0.001 & $0.60(0.45,0.82)$ & $85 \%$ & $45.9 \% / 70 \%$ \\
\hline Follow-up $\geq 4$ years & 1 & $611 / 629$ & $305 / 437$ & $<0.00001$ & $0.72(0.65,0.79)$ & - & $49.9 \% / 69.5 \%$ \\
\hline \multicolumn{8}{|l|}{ Type of MM } \\
\hline CA vs. rhythm control & 14 & $992 / 863$ & $291 / 617$ & $<0.00001$ & $0.38(0.30,0.49)$ & $76 \%$ & $29.3 \% / 71.5 \%$ \\
\hline CA vs. rate control & 4 & $104 / 101$ & $18 / 99$ & 0.008 & $0.17(0.05,0.63)$ & $88 \%$ & $17.3 \% / 98 \%$ \\
\hline \multicolumn{8}{|l|}{ Number of ablation } \\
\hline Single ablation & 12 & $756 / 606$ & $311 / 481$ & $<0.00001$ & $0.51(0.45,0.58)$ & $46 \%$ & $41.1 \% / 79 \%$ \\
\hline Multiple ablations & 19 & $2330 / 2102$ & $804 / 1401$ & $<0.00001$ & $0.45(0.38,0.54)$ & $83 \%$ & $34.5 \% / 66.7 \%$ \\
\hline \multicolumn{8}{|l|}{ Type of AF } \\
\hline Paroxysmal AF & 7 & $864 / 799$ & $287 / 527$ & 0.0001 & $0.43(0.29,0.66)$ & $93 \%$ & $33.2 \% / 66 \%$ \\
\hline Persistent AF & 8 & $803 / 743$ & $308 / 475$ & $<0.00001$ & $0.54(0.44,0.68)$ & $66 \%$ & $38.4 \% / 63.9 \%$ \\
\hline \multicolumn{8}{|l|}{ Level of LVEF } \\
\hline Normal LVEF & 19 & $1966 / 1675$ & $696 / 1116$ & $<0.00001$ & $0.44(0.37,0.54)$ & $83 \%$ & $35.4 \% / 66.6 \%$ \\
\hline Reduced LVEF & 8 & $567 / 566$ & $186 / 409$ & $<0.00001$ & $0.42(0.30,0.60)$ & $81 \%$ & $32.8 \% / 72.2 \%$ \\
\hline
\end{tabular}

AF: atrial fibrillation; CA: catheter ablation; CI: confidence interval; LVEF: left ventricular ejection fraction; MM: medical management; RR: risk ratio.

ference was found in the risk for stroke/TIA directly induced by AF itself in the two groups (RR: $0.70 ; 95 \% \mathrm{CI}: 0.39$ to $1.23, P=$ $0.21 ; I^{2}=0 \%$ ). Furthermore, 13 strokes/TIAs were associated with the ablation procedure, and CA was found to increase the periprocedure stroke/TIA risk (RR: 3.10 ; $95 \% \mathrm{CI}: 1.05$ to $9.18, P=$ $0.04 ; I^{2}=0 \%$ ) (Fig. 6).

Similarly, CA significantly increased the risk of major bleeding (RR: 3.88 ; $95 \%$ CI: 1.63 to $9.22, P=0.002 ; I^{2}=0 \%$ ), pulmonary vein stenosis (RR: 3.94 ; $95 \% \mathrm{CI}: 1.49$ to $10.38, P=0.006$; $I^{2}=0 \%$ ), and pericardial complications (RR: 4.63 ; 95\% CI: 2.33 to $9.17, P<0.0001 ; I^{2}=0 \%$ ) compared with MM (Fig. 7). The overall incidence of complications was 104 out of 3051 (3.4\%), distributed as follows: $2(0.06 \%)$ deaths, $13(0.4 \%)$ strokes/TIAs, $22(0.7 \%)$ major bleeding, $25(0.8 \%)$ pulmonary vein stenosis, 42 (1.4\%) pericardial complications. Details of CA-related complications are listed in Table 3.

At the last follow-up, the pooled incidence of recurrent atrial arrhythmia was $41.1 \%$ after a single ablation and $34.5 \%$ after multiple ablations. The multiple ablations long-term recurrence of atrial arrhythmia in paroxysmal AF was $33.2 \%$ in 7 studies, and that in persistent AF was $38.4 \%$ in 8 studies. Patients underwent multiple procedures with the mean number of ablations ranging from 1.19 to 1.7 . The recurrence rate reached the maximum (49.9\%) when the follow-up time reached 48 months or more. Compared with rhythm control or rate control, CA was associated with a significantly reduced risk of recurrent atrial arrhythmia at follow-up [(RR: 0.38 ; $95 \%$ CI: 0.30 to $0.49, P<0.00001$; $I^{2}=76 \%$ ) (RR: $0.17 ; 95 \%$ CI: 0.05 to $0.63, P=0.08 ; I^{2}=88 \%$ )]. The benefit of CA compared with MM in reducing recurrence was consistent among patients with HF (RR: 0.42 ; $95 \%$ CI: 0.30 to $0.60, P<0.00001 ; I^{2}=81 \%$ ) and Non-HF (RR: $0.44 ; 95 \%$ CI: 0.37 to $0.54, P<0.00001 ; I^{2}=83 \%$ ). Details of outcome for recurrence of atrial arrhythmia in AF patients with normal or reduced LVEF who underwent $\mathrm{CA}$ or $\mathrm{MM}$ in the included studies are summarized in Table 4 .

\subsection{Publication Bias}

The probability of potential publication bias in the 26 studies was estimated by using Begg's funnel plots (Fig. 8) and Egger's linear regression method ( $P=0.623$ with $95 \%$ CI: -0.486 to 0.781 ). The results showed a very low probability of publication bias.

\section{Discussion}

Our meta-analysis gave the following results:

(1) There was no significant difference in all-cause mortality among AF patients with non-HF or AHF in the two arms of the analysis, while patients with $\mathrm{HF}$ receiving CA treatment and patients who were followed up for more than 12 months had a significantly lower rate of all-cause mortality.

(2) CA increased the risk of hospitalization when used as firstline therapy but decreased the risk for hospitalization when used as second-line therapy.

(3) There was no significant difference regarding the risk for stroke directly induced by AF itself between the treatment groups. AF patients treated with CA had a higher incidence of periprocedural stroke, major bleeding, pulmonary vein stenosis, and pericardial complications, while recurrent atrial arrhythmia was a lower risk.

$\mathrm{AF}$ and $\mathrm{HF}$ are common forms of heart disease which are associated with high rates of mortality and morbidity. AF patients with HF have even higher mortality and hospitalization rates, irrespective of which disease occurred first (Dyrda et al., 2015; Steinberg et al., 2014). Current data shows that successful AF ablation 
A

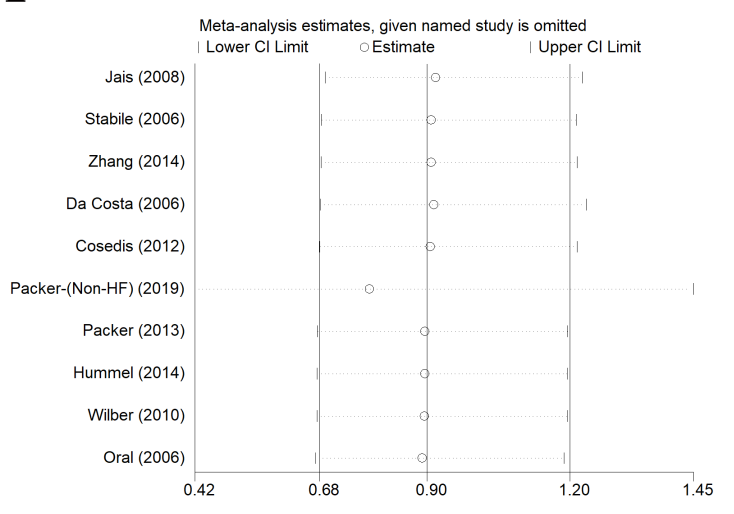

B

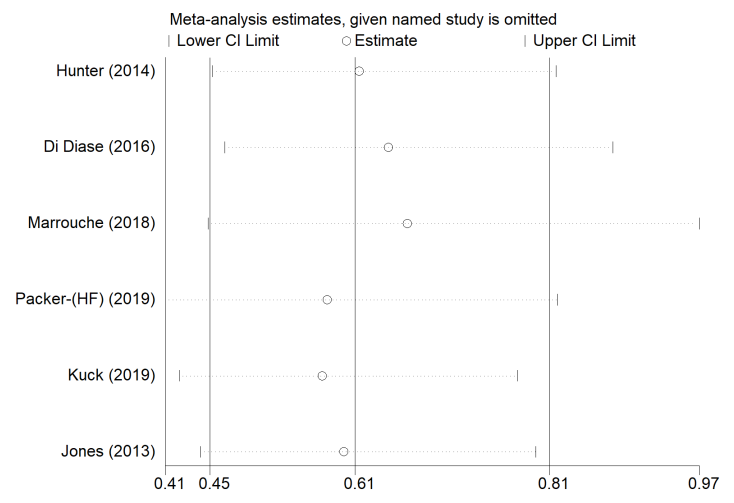

C

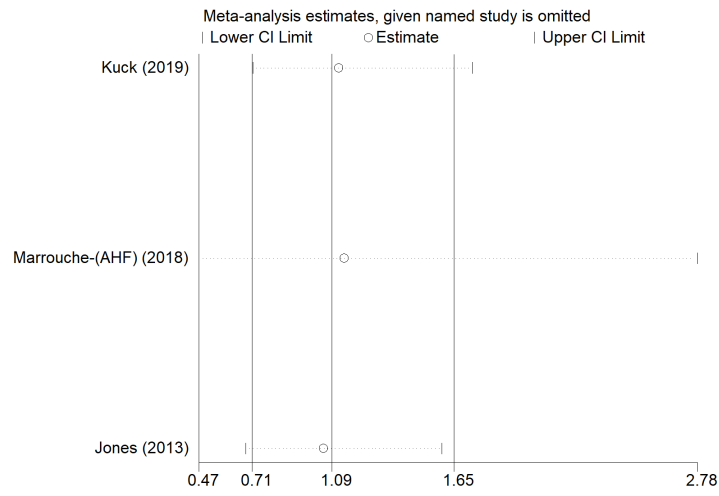

Fig. 3. Sensitivity analysis for all-cause mortality. (A) Sensitivity analysis for all-cause mortality among patients without HF. (B) Sensitivity analysis for all-cause mortality among patients with HF. (C) Sensitivity analysis for all-cause mortality among patients with AHF.

has improved LVEF in such patients (Khan et al., 2018; Prabhu et al., 2017). A possible reason for that finding is an improvement in cardiac hemodynamics achieved by restoring SR since HF patients rely more on atrial contraction to maintain an adequate cardiac output, and reduce the likelihood of developing tachycardia-mediated cardiomyopathy (Redfield et al., 2000). Our meta-analysis showed a significant reduction in mortality when CA rather than MM was used for treating AF patients with HF. Meanwhile, this survival benefit of CA was mainly in trials with a follow-up time $>12$ months. Conversely, CA had no mortality advantage in short follow-up duration or in patients without HF, which can perhaps be explained by the low event rates. Our analysis also detected a $0.06 \%$ peri-procedural mortality with CA, in accord with prior investigations $(0.06 \%$ to $0.3 \%)$ (Arbelo et al., 2014). The studies conducted by Di Biase et al. (2016) and Marrouche et al. (2018) included AF patients with HF, and that factor largely contributed to the pooled beneficial effect. The study by Prabhu et al. (2017) enrolled patients with persistent AF accompanied by idiopathic cardiomyopathy. Ventricular function increased significantly in these patients, particularly in the patients without ventricular fibrosis as detected by cardiac magnetic resonance after ablation. In a recent study by Packer et al. (2019), CA was associated with reductions in the risks for composite death, disabling stroke, serious bleeding, and cardiac arrest; but those reductions were not statistically significant. However, in the HF subgroup significant results favoring CA over MM were found. Moreover, in AF patients with HF, drug treatment is restricted to dofetilide or amiodarone, either of which can cause serious adverse reactions. Hence, the potential benefits of ablation in this scenario may be further expanded. In the study by Marrouche et al. (2018), which has some major defects such as a large number of patients lost to follow-up, the significant finding of reduced mortality needs to be interpreted very cautiously. However, our meta-analysis also revealed that the AF patients with AHF accompanied by severely reduced LVEF did not benefit from CA. MacDonald et al. (2011) conducted the first RCT that enrolled patients with AF and AHF, and showed that only 50\% of the patients successfully maintained SR with no improvement in LVEF. In a study by Kuck et al. (2019), although at any time during the follow-up, patients in the ablation group had a higher SR and lower AF burden, the level of LVEF elevation (8.8\%) in the ablation patients was almost identical to that in MM patients (7.3\%) over a one year period. This was further supported by a subgroup analysis of the primary end point in the study by Marrouche et al. (2018), in which patients with a LVEF $<25 \%$ did not show any benefit from CA. Taken together, it can be concluded that the degree of $\mathrm{HF}$ at baseline affects the efficacy of CA in treating AF in $\mathrm{HF}$ patients, and the benefits provided by ablation in patients with serious $\mathrm{AHF}$ are quite limited. In other words, while AF ablation reduces the mortality rate of patients who have less severe AHF and better LVEF, it does not uniformly benefit all AF patients.

Our preliminary analysis favored CA over MM for decreasing the risk for hospitalization when CA was used as second-line therapy. Data shows that while the average length of a hospital stay has remained unchanged, the cost of inpatient care has increased in recent years (Patel et al., 2014). As a result, it is very important to reduce the current hospitalization rate and associated treatment costs. Similarly, data also suggest that a reduction in hospitalizations, a core indicator of health care utilization, could have important socioeconomic effects (Nisar et al., 2018). On the other 


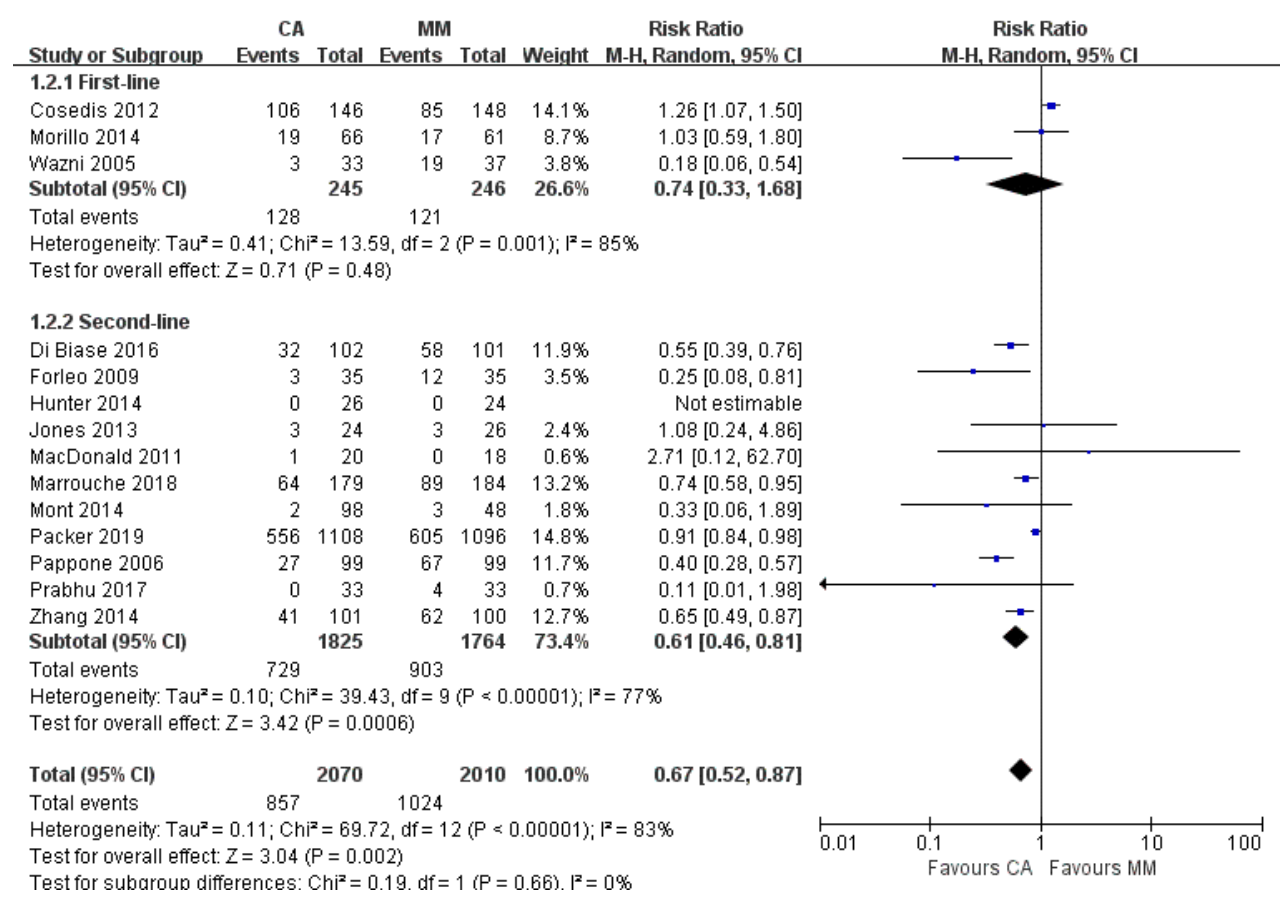

Fig. 4. The pooled outcome of hospitalization risk for patients treated with CA versus MM. A forest plot illustrating results of the subgroup analysis that was performed based on CA provided as first-line or second-line therapy (upper panel shows the pooled outcome for CA when used as first-line therapy; lower panel shows the pooled outcome for CA when used as second-line therapy).

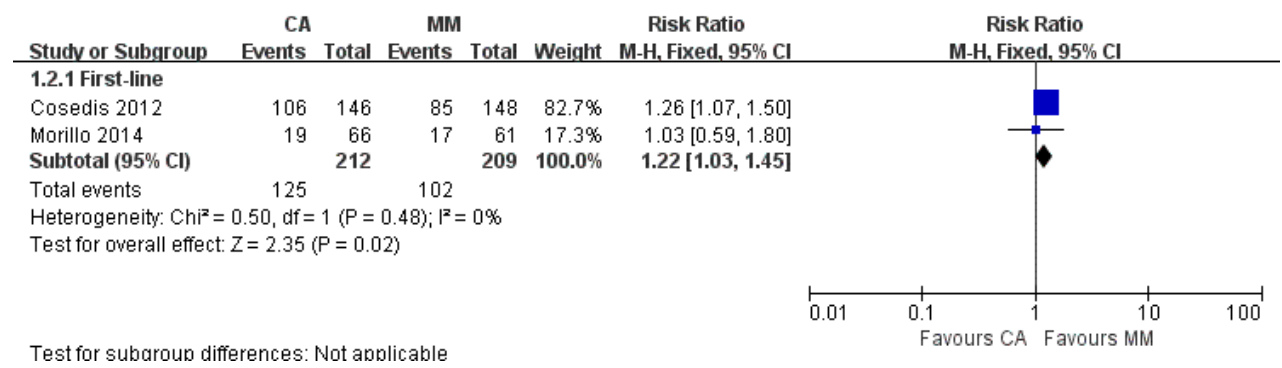

Fig. 5. The pooled outcome of hospitalization risk when CA was used as first-line therapy. A forest plot illustrating the risk of hospitalization when CA was performed as first-line treatment, after excluding the study by Wazni et al. (2005).

hand, when performed as initial therapy, CA may not be more expensive than MM (Khaykin et al., 2009), and result in a lower rate of recurrent atrial arrhythmias (Morillo et al., 2014). However, our meta-analysis revealed that CA, when used as first-line therapy, increased the risk for hospitalization. Furthermore, our report also suggested a significantly higher incidence of peri-procedure stroke, major bleeding, pulmonary vein stenosis, and pericardial complications with CA. These CA-related complications usually are more immediate and dramatic than those with MM. Therefore, the risks and benefits of performing CA as initial treatment for AF should be fully considered and understood. The current ongoing early invasive intervention study of AF (EARLY-AF trail) will once again evaluate the optimal first management approach for patients with AF (Andrade et al., 2018).

Regarding the result for stroke, 13 strokes/TIAs were associated with an ablation procedure, and 4 occurred in the study by Hummel et al. (2014), which used a phased radiofrequency ablation approach. Evidence exists for an increased peri-procedural stroke risk (Herrera et al., 2011). In our analysis, the peri-procedural stroke risk was $0.4 \%$, which is similar to that documented by $\mathrm{Ar}$ belo et al. (2014), and suggests that stroke remains a significant complication of AF ablation. It has been suggested that successful CA and recovery of SR, although closely related to an increased risk for asymptomatic cerebral infarction, may subsequently reduce the burden of embolism over time (Asirvatham and Friedman, 2006; Thakur et al., 2016). Indeed, in a study by Nademanee et al. (2008), the stroke/TIA regression models showed significant differences in events between groups after one year of follow-up. However, our meta-analysis failed to show any strong evidence for a reduction in long-term stroke risk. The high crossover rate from $\mathrm{MM}$ to CA and relatively low number of cerebrovascular events may in our included studies have made the reduction in long-term stroke risk unrecognizable. These results should be interpreted with caution because some of the included trials did not report the type of anticoagulation strategy used during follow-up. The current ongoing Early Treatment of AF for Stroke Prevention (EAST) trial will provide much-needed evidence in this field (Kirchhof et al., 2013). 


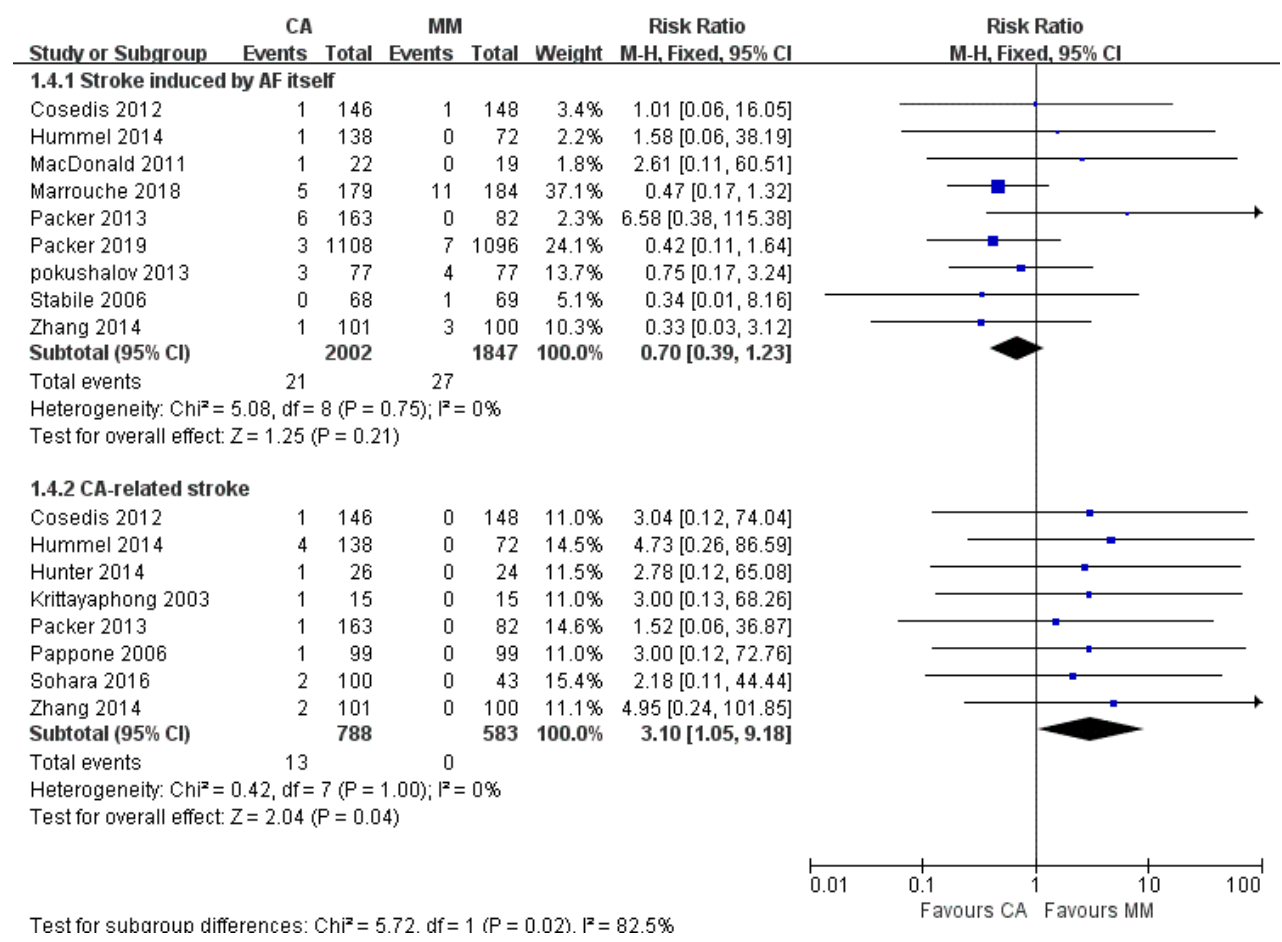

Fig. 6. The pooled outcome of stroke/TIA risk associated with CA versus MM. The forest plot illustrates results of a subgroup analysis that was performed based on the source of stroke (upper panel shows the pooled outcome for stroke directly induced by AF itself; lower panel shows the pooled outcome for stroke caused by ablation procedure).

Current published reports indicate variable efficacy of CA for different groups of patients with AF (i.e., paroxysmal or persistent AF) (Ganesan et al., 2013; Shi et al., 2015). Subsequently, the superior efficacy of CA in reducing the risk of recurrent atrial arrhythmia in patients with paroxysmal or persistent $\mathrm{AF}$ in our analysis suggests that CA can be considered as a suitable treatment for all types of AF. However, significant heterogeneity was also found in this result $\left(I^{2}>50 \%\right)$, which is likely to reflect differences across included trials with regards to the procedural techniques, operators' skills, definitions of failure outcomes, and arrhythmia tracking methods. Additionally, it is worth noting that a significant proportion of study patients underwent multiple ablations (per patient ranging from 1.19-1.7). Even if initial ablation is successful, the underlying pathophysiology that leads to the initial onset of AF may increase the likelihood of recurrence. Work needs to be done to understand whether risk factor management, with or without ablation, can reduce recurrence rates.

Previous studies have shown that CA is superior to MM alone for preventing a recurrence of $\mathrm{AF}$, improving a patient's quality of life, and reducing morbidity (Choi et al., 2010; Gentlesk et al., 2007). Therefore, it may seem legitimate believe that successful AF ablation will lead to reductions in clinical hard endpoints. In fact, our meta-analysis showed contradictory results. Rhythm control and rate control are two highly debated topics in AF management. In theory, rhythm control with better atrial pump function, a relatively normal ventricular rate, and regular rhythm should provide for a better prognosis. However, the studies by Hagens et al. (2005), Roy et al. (2008) and Wyse et al. (2002) indicate that regardless of whether it is implemented by use of AADs or cardioversion, a rhythm control strategy does not provide an advan- tage in terms of clinical hard endpoints. One reason may be that a rhythm control strategy does not completely maintain SR. With advances in technology, CA has become an effective method for treating AF. Our meta-analysis supporting the use of CA for reducing mortality was mostly confined to HF patients with moderately depressed LVEF. In this subgroup of patients, and especially those treated with ablation technology at skilled research centers, ablation rather than MM can be used for the objective of improving a patient's prognosis. The study by Packer et al. (2019) remains the largest RCT to compare CA with MM for treatment of AF. Patients enrolled in that trial who had a risk factor for stroke were relatively "low risk" patients when compared to patients enrolled in two trials conducted by Di Biase et al. (2016) and Marrouche et al. (2018), and the results showed that although CA had a higher SR maintenance rate, it did not benefit clinical hard endpoints. One on hand, this suggests that rhythm control may be just a type of symptomatic treatment that does not address the underlying cause of AF. On the other hand, the technical bottleneck of CA needs to be broken (e.g., additional ganglion ablation, rotor ablation, experience and data on cryoablation by ice balloon), as only in this manner can we fully understand the advantages and limitations of a rhythm control strategy.

\section{Strengths and limitations}

This is the latest pooled analysis with a large sample size and enhanced statistical power. All the RCTs included in our analysis were of high methodological quality. Because recent metaanalyses have only assessed AF patients with HF (Asad et al., 2019; Chen et al., 2019; Ruzieh et al., 2019; Virk et al., 2019), we included studies that enrolled AF patients without HF and with AHF. In ad- 


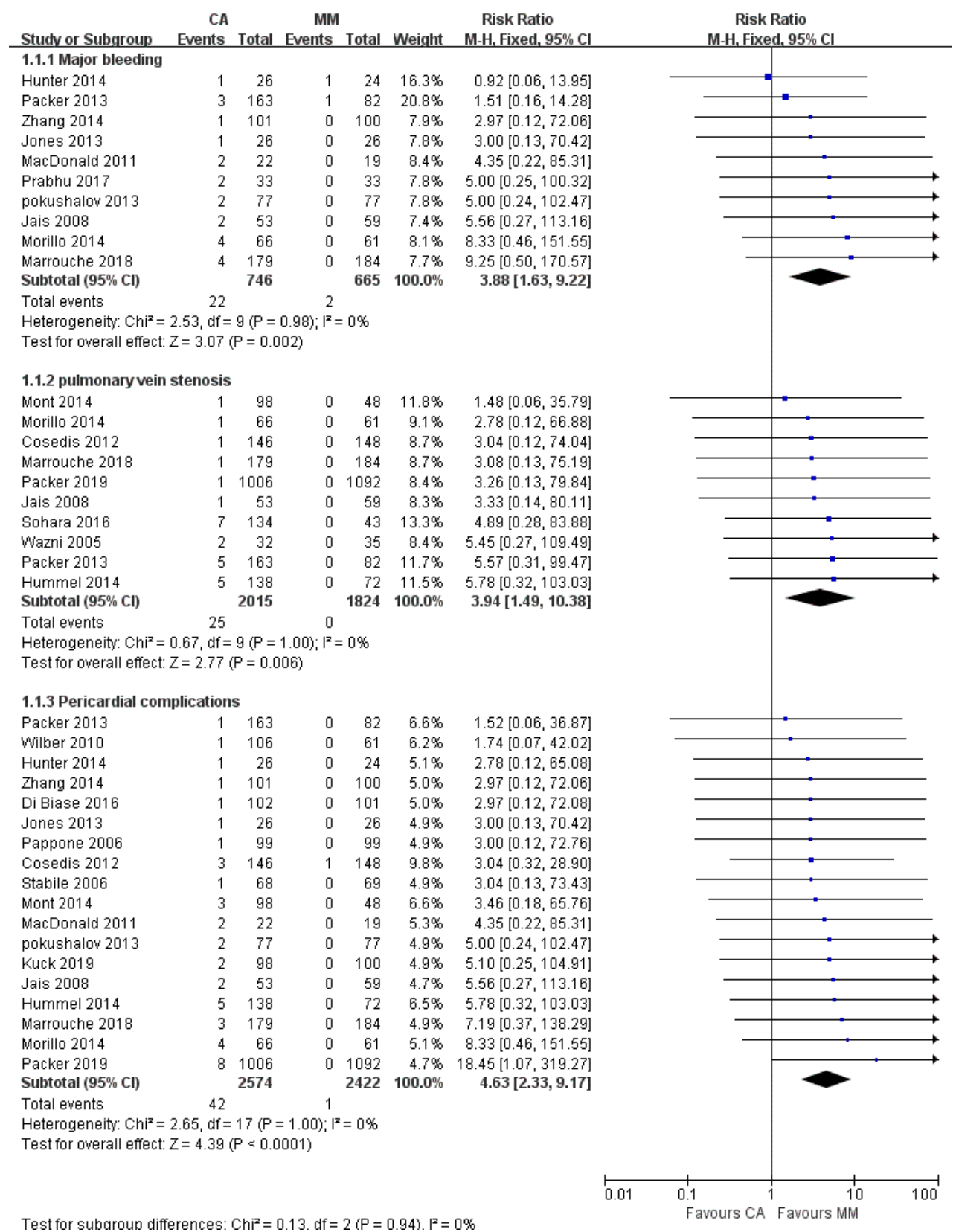

Fig. 7. The pooled outcome of peri-procedural complications in the CA group versus the MM group. The forest plot illustrates results of the stratification analysis that was performed based on the types of complications (upper panel shows the pooled outcome for major bleeding, the middle panel shows the pooled outcome for pulmonary vein stenosis, and lower panel shows the pooled outcome for pericardial complications).

dition, a sensitivity analysis was conducted, and the results showed very good stability regarding our findings for all-cause mortality. Furthermore, we explored the source of the heterogeneity regarding hospitalization rates. Despite these advantages, our analysis still has some limitations that cannot be ignored. First, a number of small sample-size studies and studies with short follow-up periods were included in the pooled analysis. Second, due to the lack of individual patient data, a meta-regression could not be performed to assess the impact of confounding factors. Our findings were also likely affected by several other factors, including the technique used for ablation, the drugs used, the type or dose of anticoagulant used, the pattern of $\mathrm{AF}$, and the follow-up duration, which may have led to the heterogeneity encountered in our analysis.

\section{Conclusions}

In this meta-analysis, the effect of $\mathrm{AF}$ ablation depended on the baseline level of LVEF in the HF patients. AF ablation appears to be of benefit to patients with a lesser degree of AHF and better LVEF by reducing mortality. Meanwhile, this mortality advantage was manifested in long-term follow-up. CA increased the risk for hospitalization when it was used as first-line therapy and decreased the risk when used as second-line therapy. CA reduced recurrence of atrial arrhythmia for different types of AF (paroxysmal or persistent AF) and CA-related complications were non- 


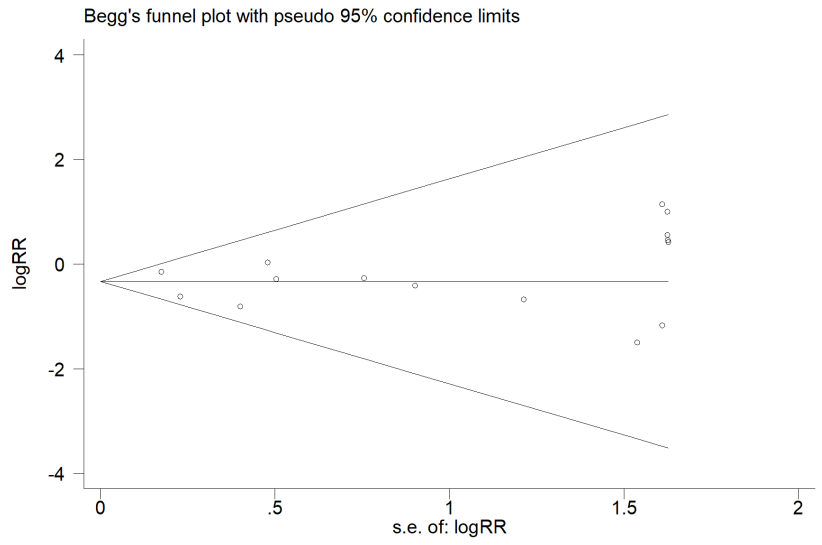

Fig. 8. A Begg's funnel plot of all studies included in the meta-analysis. The absence of asymmetry indicates that there was no publication bias.

negligible. There was no convincing evidence for a reduction in long-term stroke risk after AF ablation, and additional high quality RCTs are needed to address that issue.

\section{Authors' contributions}

M-YJ and WH made the primary contribution in literature search, data collection, table drawing, and manuscript drafting/revisions. C-JX made main contribution in language editing, references sorting, and manuscript drafting/revisions. H-PF made the contribution to study conception, data interpretation and manuscript revisions. All authors contributed to the interpretation of results, revising themanuscript critically for important intellectual content, and all approved the final manuscript.

\section{Acknowledgments}

I would like to express my gratitude to all those who assisted me with writing this manuscript. I also thank the peer reviewers and editors for their comments and suggestions.

\section{Conflict of interest}

All authors declare having no conflict of interest.

Submitted: April 14, 2020

Revised: June 25, 2020

Accepted: July 09, 2020

Published: September 30, 2020

\section{References}

Andrade, J. G., Champagne, J., Deyell, M. W., Essebag, V., Lauck, S., Morillo, C., Sapp, J., Skanes, A., Theoret-Patrick, P., Wells, G. A. and Verma, A. (2018) A randomized clinical trial of early invasive intervention for atrial fibrillation (EARLY-AF) - methods and rationale. American Heart Journal 206, 94-104.

Arbelo, E., Brugada, J., Hindricks, G., Maggioni, A. P., Tavazzi, L., Vardas, P., Laroche, C., Anselme, F., Inama, G., Jais, P., Kalarus, Z., Kautzner, J., Lewalter, T., Mairesse, G. H., Perez-Villacastin, J., Riahi, S., Taborsky, M., Theodorakis, G. and Trines, S. A. (2014) The atrial fibrillation ablation pilot study: a European Survey on Methodology and results of catheter ablation for atrial fibrillation conducted by the European Heart Rhythm Association. European Heart Journal 35, 1466-1478.

Asad, Z. U. A., Yousif, A., Khan, M. S., Al-Khatib, S. M. and Stavrakis, S. (2019) Catheter ablation versus medical therapy for atrial fibrillation. Circulation: Arrhythmia and Electrophysiology 12, e007414.
Asirvatham, S. J. and Friedman, P. A. (2006) Silent cerebral thromboembolism with left atrial ablation: a lurking danger. Journal of Cardiovascular Electrophysiology 17, 8-10.

Chen, S., Pürerfellner, H., Meyer, C., DZHK (German Centre for Cardiovascular Research), Partner Site HamburgKielLübeck, Germany, Acou, W., Schratter, A., Ling, Z., Liu, S., Yin, Y., Martinek, M., Kiuchi, M. G., Schmidt, B. and Chun, K. R. J. (2019) Rhythm control for patients with atrial fibrillation complicated with heart failure in the contemporary era of catheter ablation: a stratified pooled analysis of randomized data. European Heart Journal (in press).

Chiang, C., Okumura, K., Zhang, S., Chao, T., Siu, C., Wei Lim, T., Saxena, A., Takahashi, Y. and Siong Teo, W. (2017) 2017 consensus of the asia pacific heart rhythm society on stroke prevention in atrial fibrillation. Journal of Arrhythmia 33, 345-367.

Choi, A. D., Hematpour, K., Kukin, M., Mittal, S. and Steinberg, J. S (2010) Ablation vs medical therapy in the setting of symptomatic atrial fibrillation and left ventricular dysfunction. Congestive Heart Failure 16, 10-14.

Chugh, S. S., Havmoeller, R., Narayanan, K., Singh, D., Rienstra, M., Benjamin, E. J., Gillum, R. F., Kim, Y., McAnulty, J. H., Zheng, Z., Forouzanfar, M. H., Naghavi, M., Mensah, G. A., Ezzati, M. and Murray, C. J. L. (2014) Worldwide epidemiology of atrial fibrillation. Circulation 129, 837-847.

Da Costa, A., Thévenin, J., Roche, F., Romeyer-Bouchard, C., Abdellaoui, L., Messier, M., Denis, L., Faure, E., Gonthier, R., Kruszynski, G., Pages, J. M., Bonijoly, S., Lamaison, D., Defaye, P., Barthélemy, J. C., Gouttard, T., Isaaz, K. and Loire-Ardèche-Drôme-Isère-Puy-de-Dôme Trial of Atrial Flutter Investigators (2006). Results from the LoireArdèche-Drôme-Isère-Puy-de-Dôme (LADIP) trial on atrial flutter, a multicentric prospective randomized study comparing amiodarone and radiofrequency ablation after the first episode of symptomatic atrial flutter. Circulation 114, 1676-1681.

Di Biase, L., Mohanty, P., Mohanty, S., Santangeli, P., Trivedi, C., Lakkireddy, D., Reddy, M., Jais, P., Themistoclakis, S., Dello Russo, A., Casella, M., Pelargonio, G., Narducci, M. L., Schweikert, R., Neuzil, P., Sanchez, J., Horton, R., Beheiry, S., Hongo, R., Hao, S., Rossillo, A., Forleo, G., Tondo, C., Burkhardt, J. D., Haissaguerre, M. and Natale, A. (2016) Ablation versus amiodarone for treatment of persistent atrial fibrillation in patients with congestive heart failure and an implanted device. Circulation 133, 1637-1644.

Dyrda, K., Roy, D., Leduc, H., Talajic, M., Stevenson, L. W., Guerra, P. G., Andrade, J., Dubuc, M., Macle, L., Thibault, B., Rivard, L., Khairy, P. and Montreal Heart Institute Coordinating Center (MHICC); Montreal QC Canada (2015) Treatment failure with rhythm and rate control strategies in patients with atrial fibrillation and congestive heart failure: an AF-CHF substudy. Journal of Cardiovascular Electrophysiology 26, 1327-1332.

Egger, M., Smith, G. D., Schneider, M. and Minder, C. (1997) Bias in meta-analysis detected by a simple, graphical test. Bmj 315, 629-634.

Forleo, G. B., Mantica, M., De Luca, L., Leo, R., Santini, L., Panigada, S., De Sanctis, V., Pappalardo, A., Laurenzi, F., Avella, A., Casella, M., Dello Russo, A., Romeo, F., Pelargonio, G. and Tondo, C. (2009) Catheter ablation of atrial fibrillation in patients with diabetes mellitus type 2: results from a randomized study comparing pulmonary vein isolation versus antiarrhythmic drug therapy. Journal of Cardiovascular Electrophysiology 20, 22-28.

Ganesan, A. N., Shipp, N. J., Brooks, A. G., Kuklik, P., Lau, D. H., Lim, H S., Sullivan, T., Roberts-Thomson, K. C. and Sanders, P. (2013) Longterm outcomes of catheter ablation of atrial fibrillation: a systematic review and meta-analysis. Journal of the American Heart Association 2, e004549.

Gentlesk, P. J., Sauer, W. H., Gerstenfeld, E. P., Lin, D., Dixit, S., Zado, E., Callans, D. and Marchlinski, F. E. (2007) Reversal of left ventricular dysfunction following ablation of atrial fibrillation. Journal of Cardiovascular Electrophysiology 18, 9-14.

Hagens, V. E., Crijns, H. J. G. M., Van Veldhuisen, D. J., Van Den Berg, M. P., Rienstra, M., Ranchor, A. V., Bosker, H. A., Kamp, O., Tijssen, J. G. P., Veeger, N. J. G. M. and Van Gelder, I. C. (2005) Rate control 
versus rhythm control for patients with persistent atrial fibrillation with mild to moderate heart failure: Results from the RAte Control versus Electrical cardioversion (RACE) study. American Heart Journal 149, 1106-1111.

Hart, R. G., Pearce, L. A. and Aguilar, M. I. (2007) Meta-analysis: antithrombotic therapy to prevent stroke in patients who have nonvalvular atrial fibrillation. Annals of Internal Medicine 146, 857.

Herrera, S. C., Deneke, T., Hocini, M., Lehrmann, H., Shin, D., Miyazaki, S., Henschke, S., Fluegel, P., Schiebeling-Römer, J., Bansmann, P. M., Bourdias, T., Dousset, V., Haïssaguerre, M. and Arentz, T. (2011) Incidence of Asymptomatic Intracranial Embolic Events After Pulmonary Vein Isolation. Journal of the American College of Cardiology 58, 681688.

Higgins, J. P. T., Altman, D. G., Gotzsche, P. C., Juni, P., Moher, D., Oxman, A. D., Savovic, J., Schulz, K. F., Weeks, L., Sterne, J. A C., Cochrane Bias Methods Group and Cochrane Statistical Methods Group (2011) The Cochrane Collaboration's tool for assessing risk of bias in randomised trials. BMJ 343, d5928-d5928.

Hummel, J., Michaud, G., Hoyt, R., DeLurgio, D., Rasekh, A., Kusumoto, F., Giudici, M., Dan, D., Tschopp, D., Calkins, H. and Boersma, L. (2014) Phased RF ablation in persistent atrial fibrillation. Heart Rhythm 11, 202-209.

Hunter, R. J., Berriman, T. J., Diab, I., Kamdar, R., Richmond, L., Baker, V., Goromonzi, F., Sawhney, V., Duncan, E., Page, S. P., Ullah, W., Unsworth, B., Mayet, J., Dhinoja, M., Earley, M. J., Sporton, S. and Schilling, R. J. (2014) A randomized controlled trial of catheter ablation versus medical treatment of atrial fibrillation in heart failure (The CAMTAF Trial). Circulation: Arrhythmia and Electrophysiology 7, 31-38.

Jais, P., Cauchemez, B., Macle, L., Daoud, E., Khairy, P., Subbiah, R., Hocini, M., Extramiana, F., Sacher, F., Bordachar, P., Klein, G., Weerasooriya, R., Clémenty, J. and Haïssaguerre, M. (2008) Catheter ablation versus antiarrhythmic drugs for atrial fibrillation. Circulation 118, 2498-2505.

Jones, D. G., Haldar, S. K., Hussain, W., Sharma, R., Francis, D. P., Rahman-Haley, S. L., McDonagh, T. A., Underwood, S. R., Markides, V. and Wong, T. (2013) A randomized trial to assess catheter ablation versus rate control in the management of persistent atrial fibrillation in heart failure. Journal of the American College of Cardiology 61, 1894 1903.

Khan, S. U., Rahman, H., Talluri, S. and Kaluski, E. (2018) The clinical benefits and mortality reduction associated with catheter ablation in subjects with atrial fibrillation: a systematic review and meta-analysis. Journal of the American College of Cardiology-Clinical Electrophysiology 4, 626-635

Khaykin, Y., Wang, X., Natale, A., Wazni, O. M., Skanes, A. C., Humphries, K. H., Kerr, C. R., Verma, A. and Morillo, C. A. (2009) Cost comparison of ablation versus antiarrhythmic drugs as first-line therapy for atrial fibrillation: an economic evaluation of the RAAFT pilot study. Journal of Cardiovascular Electrophysiology 20, 7-12.

Kirchhof, P., Benussi, S., Kotecha, D., Ahlsson, A., Atar, D., Casadei, B., Castella, M., Diener, H., Heidbuchel, H., Hendriks, J., Hindricks, G., Manolis, A. S., Oldgren, J., Popescu, B. A., Schotten, U., Putte, B. V. and Vardas, P. (2016) 2016 ESC Guidelines for the management of atrial fibrillation developed in collaboration with EACTS. . European Heart Journal 37, 2893-2962.

Kirchhof, P., Breithardt, G., Camm, A. J., Crijns, H. J., Kuck, K., Vardas, P. and Wegscheider, K. (2013) Improving outcomes in patients with atrial fibrillation: Rationale and design of the Early treatment of Atrial fibrillation for Stroke prevention Trial. American Heart Journal 166, 442-448.

Krittayaphong, R., Raungrattanaamporn, O., Bhuripanyo, K., Sriratanasathavorn, C., Pooranawattanakul, S., Punlee, K. and Kangkagate, C. (2003) A randomized clinical trial of the efficacy of radiofrequency catheter ablation and amiodarone in the treatment of symptomatic atrial fibrillation. Journal of the Medical Association of Thailand 86 Suppl 1, S8-16.

Kuck, K., Merkely, B., Zahn, R., Arentz, T., Seidl, K., Schlüter, M., Tilz, R. R., Piorkowski, C., Gellér, L., Kleemann, T. and Hindricks, G.
(2019) Catheter ablation versus best medical therapy in patients with persistent atrial fibrillation and congestive heart failure. Circulation: Arrhythmia and Electrophysiology 12, e007731.

Lloyd-Jones, D. M., Wang, T. J., Leip, E. P., Larson, M. G., Levy, D., Vasan, R. S., D’Agostino, R. B., Massaro, J. M., Beiser, A., Wolf, P. A. and Benjamin, E. J. (2004) Lifetime risk for development of atrial fibrillation. Circulation 110, 1042-1046.

MacDonald, M. R., Connelly, D. T., Hawkins, N. M., Steedman, T., Payne, J., Shaw, M., Denvir, M., Bhagra, S., Small, S., Martin, W., McMurray, J. J. V. and Petrie, M. C. (2011) Radiofrequency ablation for persistent atrial fibrillation in patients with advanced heart failure and severe left ventricular systolic dysfunction: a randomised controlled trial. Heart 97, 740-747.

Mansour, M., Heist, E. K., Agarwal, R., Bunch, T. J., Karst, E., Ruskin, J. N. and Mahapatra, S. (2018) Stroke and cardiovascular events after ablation or antiarrhythmic drugs for treatment of patients with atrial fibrillation. The American Journal of Cardiology 121, 1192-1199.

Marrouche, N. F., Brachmann, J., Andresen, D., Siebels, J., Boersma, L., Jordaens, L., Merkely, B., Pokushalov, E., Sanders, P., Proff, J., Schunkert, H., Christ, H., Vogt, J. and Bänsch, D. (2018) Catheter ablation for atrial fibrillation with heart failure. New England Journal of Medicine 378, 417-427.

Menzies, D. (2011) Systematic reviews and meta-analyses. The International Journal of Tuberculosis and Lung Disease : the Official Journal of the International Union against Tuberculosis and Lung Disease 15, 582-593.

Mont, L., Bisbal, F., Hernández-Madrid, A., Pérez-Castellano, N., Viñolas, X., Arenal, A., Arribas, F., Fernández-Lozano, I., Bodegas, A., Cobos, A., Matía, R., Pérez-Villacastín, J., Guerra, J. M., Ávila, P., López-Gil, M., Castro, V., Arana, J. I. and Brugada, J. (2014) Catheter ablation vs. antiarrhythmic drug treatment of persistent atrial fibrillation: a multicentre, randomized, controlled trial (SARA study). European Heart Journal 35, 501-507.

Morillo, C. A., Verma, A., Connolly, S. J., Kuck, K. H., Nair, G. M., Champagne, J., Sterns, L. D., Beresh, H., Healey, J. S. and Natale, A. (2014) Radiofrequency ablation vs antiarrhythmic drugs as first-line treatment of paroxysmal atrial fibrillation (RAAFT-2). JAMA311, 692.

Nademanee, K., Schwab, M. C., Kosar, E. M., Karwecki, M., Moran, M. D., Visessook, N., Michael, A. D. and Ngarmukos, T. (2008) Clinical outcomes of catheter substrate ablation for high-risk patients with atria fibrillation. Journal of the American College of Cardiology 51, 843849

Natale, A., Newby, K. H., Pisanó, E., Leonelli, F., Fanelli, R., Potenza, D., Beheiry, S. and Tomassoni, G. (2000) Prospective randomized comparison of antiarrhythmic therapy versus first-line radiofrequency ablation in patients with atrial flutter. Journal of the American College of Cardiology 35, 1898-1904.

Nielsen, J. C., Johannessen, A., Raatikainen, P., Hindricks, G., Walfridsson, H., Kongstad, O., Pehrson, S., Englund, A., Hartikainen, J., Mortensen, L. S. and Hansen, P. S. (2012) Radiofrequency ablation as initial therapy in paroxysmal atrial fibrillation. New England Journal of Medicine 367, 1587-1595.

Nisar, M. U., Munir, M. B., Sharbaugh, M. S., Thoma, F. W., Althouse, A. D. and Saba, S. (2018) Trends in atrial fibrillation hospitalizations in the United States: A report using data from the National Hospital Discharge Survey. Indian Pacing and Electrophysiology Journal $\mathbf{1 8}$ 6-12.

Oral, H., Pappone, C., Chugh, A., Good, E., Bogun, F., Pelosi, F., Bates, E. R., Lehmann, M. H., Vicedomini, G., Augello, G., Agricola, E., Sala, S., Santinelli, V. and Morady, F. (2006) Circumferential pulmonaryvein ablation for chronic atrial fibrillation. New England Journal of Medicine 354, 934-941.

Packer, D. L., Kowal, R. C., Wheelan, K. R., Irwin, J. M., Champagne, J., Guerra, P. G., Dubuc, M., Reddy, V., Nelson, L., Holcomb, R. G., Lehmann, J. W. and Ruskin, J. N. (2013) Cryoballoon ablation of pulmonary veins for paroxysmal atrial fibrillation. Journal of the American College of Cardiology 61, 1713-1723.

Packer, D. L., Mark, D. B., Robb, R. A., Monahan, K. H., Bahnson, T. D., Poole, J. E., Noseworthy, P. A., Rosenberg, Y. D., Jeffries, N., 
Mitchell, L. B., Flaker, G. C., Pokushalov, E., Romanov, A., Bunch, T. J., Noelker, G., Ardashev, A., Revishvili, A., Wilber, D. J., Cappato, R., Kuck, K., Hindricks, G., Davies, D. W., Kowey, P. R., Naccarelli, G. V., Reiffel, J. A., Piccini, J. P., Silverstein, A. P., Al-Khalidi, H. R. and Lee, K. L. (2019) Effect of catheter ablation vs antiarrhythmic drug therapy on mortality, stroke, bleeding, and cardiac arrest among patients with atrial fibrillation: the CABANA randomized clinical trial. JAMA 321, 1261-1274.

Pappone, C., Augello, G., Sala, S., Gugliotta, F., Vicedomini, G., Gulletta, S., Paglino, G., Mazzone, P., Sora, N., Greiss, I., Santagostino, A., LiVolsi, L., Pappone, N., Radinovic, A., Manguso, F. and Santinelli, V. (2006) A randomized trial of circumferential pulmonary vein ablation versus antiarrhythmic drug therapy in paroxysmal atrial fibrillation. Journal of the American College of Cardiology 48, 2340-2347.

Patel, N. J., Deshmukh, A., Pant, S., Singh, V., Patel, N., Arora, S., Shah, N., Chothani, A., Savani, G. T., Mehta, K., Parikh, V., Rathod, A., Badheka, A. O., Lafferty, J., Kowalski, M., Mehta, J. L., Mitrani, R. D., Viles-Gonzalez, J. F. and Paydak, H. (2014) Contemporary trends of hospitalization for atrial fibrillation in the United States, 2000 through 2010. Circulation 129, 2371-2379.

Pokushalov, E., Romanov, A., De Melis, M., Artyomenko, S., Baranova, V., Losik, D., Bairamova, S., Karaskov, A., Mittal, S. and Steinberg, J. S. (2013) Progression of atrial fibrillation after a failed initial ablation procedure in patients with paroxysmal atrial fibrillation. Circulation: Arrhythmia and Electrophysiology 6, 754-760.

Prabhu, S., Taylor, A. J., Costello, B. T., Kaye, D. M., McLellan, A. J. A., Voskoboinik, A., Sugumar, H., Lockwood, S. M., Stokes, M. B., Pathik, B., Nalliah, C. J., Wong, G. R., Azzopardi, S. M., Gutman, S. J., Lee, G., Layland, J., Mariani, J. A., Ling, L., Kalman, J. M. and Kistler, P. M. (2017) Catheter ablation versus medical rate control in atrial fibrillation and systolic dysfunction. Journal of the American College of Cardiology 70, 1949-1961.

Redfield, M. M., Kay, G. N., Jenkins, L. S., Mianulli, M., Jensen, D. N. and Ellenbogen, K. A. (2000) Tachycardia-related cardiomyopathy: a common cause of ventricular dysfunction in patients with atrial fibrillation referred for atrioventricular ablation. Mayo Clinic Proceedings 75, 790-795.

Reynolds, M. R., Gunnarsson, C. L., Hunter, T. D., Ladapo, J. A., March, J. L., Zhang, M. and Hao, S. C. (2012) Health outcomes with catheter ablation or antiarrhythmic drug therapy in atrial fibrillation. Circulation: Cardiovascular Quality and Outcomes 5, 171-181.

Roy, D., Talajic, M., Nattel, S., Wyse, D. G., Dorian, P., Lee, K. L., Bourassa, M. G., Arnold, J. M. O., Buxton, A. E., Camm, A. J., Connolly, S. J., Dubuc, M., Ducharme, A., Guerra, P. G., Hohnloser, S. H., Lambert, J., Le Heuzey, J., O'Hara, G., Pedersen, O. D., Rouleau, J., Singh, B. N., Stevenson, L. W., Stevenson, W. G., Thibault, B. and Waldo, A. L. (2008) Rhythm control versus rate control for atrial fibrillation and heart failure. New England Journal of Medicine 358, 26672677.

Ruzieh, M., Foy, A. J., Aboujamous, N. M., Moroi, M. K., Naccarelli, G. V., Ghahramani, M., Kanjwal, S., Marine, J. E. and Kanjwal, K. (2019) Meta-analysis of atrial fibrillation ablation in patients with systolic heart failure. Cardiovascular Therapeutics 2019, 1-10.

Santhanakrishnan, R., Wang, N., Larson, M. G., Magnani, J. W., Mc-
Manus, D. D., Lubitz, S. A., Ellinor, P. T., Cheng, S., Vasan, R. S., Lee, D. S., Wang, T. J., Levy, D., Benjamin, E. J. and Ho, J. E. (2016) Atrial fibrillation begets heart failure and vice versa. Circulation 133, 484-492.

Shi, L., Heng, R., Liu, S. and Leng, F. (2015) Effect of catheter ablation versus antiarrhythmic drugs on atrial fibrillation: A meta-analysis of randomized controlled trials. Experimental and Therapeutic Medicine 10, 816-822.

Sohara, H., Ohe, T., Okumura, K., Naito, S., Hirao, K., Shoda, M., Kobayashi, Y., Yamauchi, Y., Yamaguchi, Y., Kuwahara, T., Hirayama, H., YeongHwa, C., Kusano, K., Kaitani, K., Banba, K., Fujii, S., Kumagai, K., Yoshida, H., Matsushita, M., Satake, S. and Aonuma, K. (2016) Hotballoon ablation of the pulmonary veins for paroxysmal AF: a multicenter randomized trial in Japan. Journal of the American College of Cardiology 68, 2747-2757.

Stabile, G., Bertaglia, E., Senatore, G., De Simone, A., Zoppo, F., Donnici, G., Turco, P., Pascotto, P., Fazzari, M. and Vitale, D. F. (2006) Catheter ablation treatment in patients with drug-refractory atrial fibrillation: a prospective, multi-centre, randomized, controlled study (Catheter Ablation For The Cure Of Atrial Fibrillation Study). European Heart Journal 27, 216-221.

Steinberg, B. A., Kim, S., Fonarow, G. C., Thomas, L., Ansell, J., Kowey, P. R., Mahaffey, K. W., Gersh, B. J., Hylek, E., Naccarelli, G., Go, A. S., Reiffel, J., Chang, P., Peterson, E. D. and Piccini, J. P. (2014) Drivers of hospitalization for patients with atrial fibrillation: results from the outcomes registry for better informed treatment of atrial fibrillation (ORBIT-AF). American Heart Journal 167, 735-742.e2.

Thakur, R. K., Hijazi, Z. M. and Natale, A. (2016) Cardioembolic Stroke. Cardiology Clinics 34, xiii-xxiv.

Virk, S. A., Bennett, R. G., Chow, C., Sanders, P., Kalman, J. M., Thomas, S. and Kumar, S. (2019) Catheter ablation versus medical therapy for atrial fibrillation in patients with heart failure: a meta-analysis of randomised controlled trials. Heart, Lung and Circulation 28, 707-718.

Wazni, O. M., Marrouche, N. F., Martin, D. O., Verma, A., Bhargava, M., Saliba, W., Bash, D., Schweikert, R., Brachmann, J., Gunther, J., Gutleben, K., Pisano, E., Potenza, D., Fanelli, R., Raviele, A., Themistoclakis, S., Rossillo, A., Bonso, A. and Natale, A. (2005) Radiofrequency ablation vs antiarrhythmic drugs as first-line treatment of symptomatic atrial fibrillation. JAMA 293, 2634.

Wilber, D. J., Pappone, C., Neuzil, P., De Paola, A., Marchlinski, F., Natale, A., Macle, L., Daoud, E. G., Calkins, H., Hall, B., Reddy, V., Augello, G., Reynolds, M. R., Vinekar, C., Liu, C. Y., Berry, S. M., Berry, D. A. and ThermoCool AF Trial Investigators, F. T. (2010) Comparison of antiarrhythmic drug therapy and radiofrequency catheter ablation in patients with paroxysmal atrial fibrillation. JAMA 303, 333.

Wyse, D. G., Waldo, A. L., DiMarco, J. P., Domanski, M. J., Rosenberg, Y., Schron, E. B., Kellen, J. C., Greene, H. L., Mickel, M. C., Dalquist, J. E. and Corley, S. D. (2002) A comparison of rate control and rhythm control in patients with atrial fibrillation. The New England Journal of Medicine 347, 1825-1833.

Zhang, X. D., Gu, J., Jiang, W. F., Zhao, L., Zhou, L., Wang, Y. L., Liu, Y. G. and Liu, X. (2014) Optimal rhythm-control strategy for recurrent atrial tachycardia after catheter ablation of persistent atrial fibrillation: a randomized clinical trial. European Heart Journal 35, 1327-1334. 